\title{
Key Factors of Stress Corrosion Cracking of X70 pipeline Steel in Simulated Deep-sea Environment: Role of Localized Strain and Stress
}

Yong Li $^{1,2, \&}$ Longfei Song ${ }^{1,2, \&}$, Feilong Sun ${ }^{1,2,3, *}$

${ }^{1}$ Corrosion and Protection Center, University of Science and Technology Beijing, Beijing, 100083, China

${ }^{2}$ Key Laboratory of Corrosion and Protection of Ministry of Education, Beijing, 100083, China

${ }^{3}$ China Building Material Test \& Certification Group Co. Ltd., Beijing, 100024, China

${ }^{\&}$ These authors contributed equally to this study and share first authorship,

*E-mail: 1203407882@qq.com

doi: $10.20964 / 2018.11 .53$

Received: 6 June 2018 / Accepted: 30 August 2018 / Published: 1 October 2018

The effect of the localized strain and stress on the stress corrosion cracking (SCC) of X70 steel in simulated seawater at $500 \mathrm{~m}$ depth was investigated by performing finite element analysis, electrochemical measurements, slow strain rate tensile (SSRT) tests, and scanning electron microscopy (SEM). The results suggested that the deformation accelerates the electrochemical reaction rate. The SCC susceptibility increases with the increase of elastic deformation, and it reaches the maximum value when stress strength increases to the yield point. .In the plastic deformation, the deformation firstly increased then reduced SCC susceptibility because of hydrogen embrittlement (HE) and Bauschinger effect. The decrease of SCC susceptibility in plastic deformation was influenced by the increase of irreversible traps. It was observed that the cracks initiated at corrosion pits.

Keywords: deep sea environment; finite element analysis; mechanical electrochemistry; stress corrosion cracking

\section{FULL TEXT}

(C) 2018 The Authors. Published by ESG (www.electrochemsci.org). This article is an open access article distributed under the terms and conditions of the Creative Commons Attribution license (http://creativecommons.org/licenses/by/4.0/). 